however, it is possible that clinicians underestimate the prevalence of these side-effects as patients do not complain.

This study highlights the selectivity of information given to patients by doctors about their medication. Clearly prospective studies need to be done to investigate the possibility that there may be differences in perception between doctors and patients with regard to the importance of side-effects and also to research the relationship between iatrogenic antipsychotic-induced dysfunction and non-adherence. The important first step, however, should be to improve the discussions with patients about the side-effects of antipsychotic drugs.

\section{References}

BRITISH NATIONAL FORMULARY (1997) British National Formulary. London: British Medical Association and the Royal Pharmaceutical Society of Great Britain.

CHAPLIN, R. (1998) Informing patients about tardive dyskinesia. Controlled trial of patient education. British Journal of Psychiatry, 172, 78-81.
HOWLAND, J. S. BAKER, M. G. \& POE,T. (1990) Does patient education cause side effects? A controlled trial. Journal of Family Practice, 3, 62-64.

KEKS, N. A. (1996) Minimising the nonextrapyramidal side-effects of antipsychotics. Acta Psychiatrica Scandinavica, 389 (suppl.), 18-24.

KEOWN, C., SLOVIC, P. \&

LICHTENSTEIN, S. (1984) Attitudes of physicians, pharmacists and laypersons towards seriousness and need for disclosure of prescription drug sideeffects. Health Psychology, 3,1-11.

LIDSKY,T. J., LABUSZEWSKI,T. \& LEVINE,

F. M. (1981) Are movement disorders

the most serious side effects of

maintenance therapy with

antipsychotic drugs. Biological

Psychiatry, 16, 1189-1194.
*Shubulade Smith Research Fellow and Honorary Senior Registrar, Institute of Psychiatry, De Crespigny Park, London SE5 8AF, Max Henderson Senior House Officer, Maudsley Hospital, Denmark Hill, London SE5 8AZ

\title{
Prescribing and monitoring of carbamazepine and valproate - a case note review
}

\author{
AIMS AND METHOD \\ To evaluate prescribing and moni- \\ toring of carbamazepine and \\ valproate to patients in secondary \\ care psychiatric units. Review of pre- \\ scription cards and medical case \\ notes. \\ RESULTS \\ Prescribing details for 433 patients \\ were recorded. Both carbamazepine \\ and valproate were widely prescribed
}

\begin{abstract}
for indications not listed in their product licences. Plasma level monitoring was not frequently undertaken, particularly with valproate. Where plasma levels were measured, apparently sub-therapeutic prescribing was found to be common. For the majority of samples, it could not be established that a true trough level had been taken. Monitoring of blood function was highly variable.
\end{abstract}

(1995) Risperidone in the treatment of patients with chronic centre doub: a multi-national, multistudy versus haloperidol. British Journal of Psychiatry, 166, 712-726.

G. D., BEASLEY, C. M., 作 haloperidol in the treatment of schizophrenia and schizoaffective and schizophreniform disorders: results of American Journal of Psychiatry, 154

WARNER, J. P., BARNES, T. R. \& HENRY, J. in patients receiving neuroleptic medication. Acta Psychiatrica Scandinavica, 93, 311-313

\footnotetext{
The anticonvulsants carbamazepine and sodium valproate are widely used in psychiatric practice. Carbamazepine is officially licensed for use in epilepsy, trigeminal neuralgia and for the prophylaxis of manic-depressive psychosis in patients unresponsive to lithium (Association of the British Pharmaceutical Industry, 1998). Valproate has a less broad licence and may legally be prescribed only for a variety of seizure disorders (Association of the British Pharmaceutical Industry, 1998). Both drugs may in practice, however, be prescribed for many of other conditions including mania and aggression. We sought to investigate off-licence use in a prescription and case note review.

Carbamazepine and valproate prescribing can be problematical because of the need for blood monitoring of plasma levels and of certain adverse effect parameters. So, alongside the primary investigation, we also undertook to evaluate the quality of prescribing and monitoring
}

of the use of these drugs when set against officially recognised standards and other published recommendations.

\section{The study}

Data were collected during a predetermined week in March 1998 by pharmacists employed in 25 secondarycare psychiatry units in south-east England. Prescription cards and case notes were examined for all in-patients admitted to hospital for the treatment of mental illness prescribed either carbamazepine or valproate. Patients' age, gender and diagnosis were taken from case notes and the reasons given for prescribing either drug recorded verbatim. Pathology report forms were searched for records of plasma level monitoring and full 
blood counts. Drug doses and formulations were noted from prescription charts.

\section{Findings}

We found prescribing details for 292 patients on carbamazepine and 141 on valproate. The age of those on carbamazepine ranged from 17-97 years (mean 46.7) and $54.4 \%$ were male. For patients taking valproate, $49.6 \%$ were male and age ranged from $19-80$ years (mean 42.5).

\section{Indications}

There were 23 recorded indications for the prescribing of carbamazepine and 13 recorded indications for prescribing sodium valproate. These were condensed into four broad indications.

(a) Mood disorder, including reasons stated as: mood stabiliser, bipolar affective disorder, hypomania, depression, seasonal affective disorder, schizoaffective disorder, antidepressant augmentation, affective and schizoaffective disorders.

\section{Table 1. Indications for prescribing, plasma level validity and full blood counts (FBCs)}

\begin{tabular}{lcc} 
Indication & Carbamazepine $(n=292)$ & Sodium valproate $(n=141)$ \\
\hline Mood disorder & $111(38.0 \%)$ & $56(40.0 \%)$ \\
Seizure disorder & $99(34.0 \%)$ & $68(48.0 \%)$ \\
Behavioural disturbance & $38(13.0 \%)$ & $6(4.0 \%)$ \\
Other indications & $44(15.0 \%)$ & $11(8.0 \%)$ \\
Validity of plasma drug levels ${ }^{1}$ & & \\
No. of patients for whom plasma samples taken $(\%)$ & $193(66.0 \%)$ & $60(42.6 \%)$ \\
True trough (\%) & $7(3.6 \%)$ & $6(10.0 \%)$ \\
Not known if true trough (\%) & $156(80.8 \%)$ & $48(80.0 \%)$ \\
Not true trough (\%) & $30(15.6 \%)$ & $5(10.0 \%)$ \\
Mean number of weeks since last plasma level taken (range) & $45.8(0-404)$ & $47(0-270)$ \\
FBC results & & \\
Number of patients for whom FBCs recorded (\%) & $226(77.4 \%)$ & $109(77.3 \%)$ \\
No. weeks since last FBC (range) & $46.9(0-439)$ & $25.8(1-270)$
\end{tabular}

1. Data collectors also recorded any stated times of blood sampling and determined whether or not these represented true 'trough' levels. The time since the last recorded plasma level was also noted.

2. FBCs are also considered necessary by some authorities. The date of last recorded FBC was noted where an FBC had been performed.

Table 2. Dose and plasma level characteristics for each indication

\begin{tabular}{|c|c|c|c|c|c|c|c|c|}
\hline \multirow[b]{2}{*}{ Characteristic } & \multicolumn{4}{|c|}{ Carbamazepine $(n=292)$} & \multicolumn{4}{|c|}{ Sodium valproate $(n=141)$} \\
\hline & $\begin{array}{l}\text { Mood } \\
(n=110)\end{array}$ & $\begin{array}{l}\text { Seizure } \\
(n=99)\end{array}$ & $\begin{array}{l}\text { Behav* } \\
(n=39)\end{array}$ & $\begin{array}{l}\text { Other } \\
(n=44)\end{array}$ & $\begin{array}{l}\text { Mood } \\
(n=56)\end{array}$ & $\begin{array}{l}\text { Seizure } \\
(n=68)\end{array}$ & $\begin{array}{l}\text { Behav* } \\
(n=6)\end{array}$ & $\begin{array}{l}\text { Other } \\
(n=11)\end{array}$ \\
\hline Dose range (mg/day) & $100-1200$ & $100-1600$ & $200-1200$ & $100-1000$ & $200-2000$ & $300-3200$ & $200-2400$ & $400-1200$ \\
\hline Mean dose (mg/day) & 556.4 & 765.15 & 643.6 & 504.5 & 886.8 & 1412.9 & 933.3 & 727.3 \\
\hline $\begin{array}{l}\text { Percentage pre- } \\
\text { scribed standard } \\
\text { tablets }\end{array}$ & 91 & 58.6 & 76.9 & 79 & 55.4 & 73.5 & 66.6 & 81.8 \\
\hline $\begin{array}{l}\text { Percentage pre- } \\
\text { scribed liquid } \\
\text { preparations }\end{array}$ & 4.5 & 6.0 & 2.6 & 13.6 & 12.5 & 10.3 & 0 & 9.0 \\
\hline $\begin{array}{l}\text { Percentage pre- } \\
\text { scribed MR preps }\end{array}$ & 4.5 & 35.4 & 20.5 & 11.4 & 32.1 & 16.2 & 33.3 & 9.1 \\
\hline $\begin{array}{l}\text { Number of patients } \\
\text { with plasma } \\
\text { samples } \\
\text { recorded (\%) }\end{array}$ & $61(55.5)$ & $81(82)$ & $26(66.7)$ & $25(56.8)$ & $21(37.5)$ & $33(48.5)$ & $2(30.0)$ & $4(36.4)$ \\
\hline $\begin{array}{l}\text { Plasma level range } \\
(\mathrm{mg} / \mathrm{l})\end{array}$ & $<0.5-15.2$ & $0.4-13.0$ & $2.7-11.5$ & $0.9-13.5$ & $11-98$ & $10-149$ & $13-81.1$ & $17-89$ \\
\hline $\begin{array}{l}\text { Mean plasma level } \\
(\mathrm{mg} / \mathrm{l})\end{array}$ & 6.6 & 7.6 & 6.2 & 5.9 & 53.1 & 60.4 & 47.1 & 44.4 \\
\hline $\begin{array}{l}\text { Percentage of } \\
\text { samples above } \\
\text { putative threshold }\end{array}$ & 44.3 & 94 & & & 52.38 & 69.7 & & \\
\hline
\end{tabular}

*Behav, behavioural disturbance. 
(b) Seizure disorder, including reason stated as: epilepsy, mood stabiliser/epilepsy, schizophrenia and epilepsy, behaviour/epilepsy and epilepsy with aggression.

original papers

(c) Behavioural disturbance, including reason stated as: behavioural control, aggression and agitation.

(d) Other indications, including reason stated as: schizophrenia, psychosis, dementia, anorexia, antipsychotic augmentation, drug-induced psychosis and post-ictal psychosis.

The relative percentages of patients prescribed the drugs for each indication are shown in Table 1.

The dose ranges, dosage forms, plasma levels and percentage of plasma levels above putative therapeutic threshold for each indication are shown in Table 2. The putative threshold for carbamazepine was taken to be $>7 \mathrm{mg} / \mathrm{l}$ for use as a mood stabiliser and $>4 \mathrm{mg} / \mathrm{l}$ for the treatment of epilepsy. The putative threshold for sodium valproate was taken to be $>50 \mathrm{mg} / \mathrm{l}$ for use as a mood stabiliser and for the treatment of epilepsy (see Comment for full details).

\section{Comment}

We surveyed treatment aspects of more than 400 mental health patients prescribed carbamazepine or valproate. A wide variety of reasons for prescribing these drugs were recorded in case notes. For carbamazepine, $34 \%$ of prescribing was for seizure disorders and 38\% for mood disorders, according to our classification. Most of this prescribing could be described as on-licence, although this was not entirely clear for many mood disorders recorded and, in addition, refractoriness to lithium was not always noted. Thus, at least $28 \%$ of carbamazepine prescribing was off-licence in this study. For valproate, at least $52 \%$ of prescribing was apparently for indications not listed in the drug's product licence. Prescribers should be aware of the potential legal consequences of adverse effects resulting from off-licence use.

The quality of carbamazepine and valproate monitoring is difficult to assess, because, for many indications, clear standards of monitoring are absent. However, most authorities would agree that plasma drug level monitoring is mandatory when using carbamazepine for seizure disorders (Eadie, 1995: Association of the British Pharmaceutical Industry, 1998) and at least helpful for valproate in seizure disorders (Balfour \& Bryson, 1994) and for both drugs in bipolar disorder (Taylor \& Duncan, 1997; Taylor et al, 1999). Given these observations, the proportion of patients in this study for whom no plasma levels had been measured is concerning. Added to this is the finding that, with the exception of carbamazepine in seizure disorders, the proportion of patients with 'therapeutic' plasma levels was surprisingly low, especially in mood disorder. For the purposes of this study therapeutic plasma level thresholds were assumed to be $4 \mathrm{mg} / \mathrm{l}$ for carbamazepine in seizure disorder (Reynolds, 1978; Association of the British Pharmaceutical Industry, 1998); $8 \mathrm{mg} / \mathrm{l}$ for carbamazepine in bipolar disorder (Taylor \& Duncan, 1997), and $50 \mathrm{mg} / \mathrm{l}$ for valproate in either condition (Taylor et al, 1999; Balfour \&
Bryson, 1994). There are apparently no clear target levels in other disorders.

Even more concerning is the apparent poor quality of sampling and record keeping. Sampling of both drugs should take place at the end of the dosing interval, so as to give a 'trough' level on which quoted therapeutic ranges and thresholds are based. In our sample, it could not be established that a true trough sample had been taken in more than $80 \%$ of cases. In fact, less than $10 \%$ were clearly true trough levels. These findings have a potentially major impact on the interpretation of blood drug levels and may even lead to inappropriate dose changes. Also, the frequency of drug level monitoring was low on average, substantially lower than recommended frequencies, even in long-term therapy (Taylor et al, 1999). Nevertheless, the mean values cited here were calculated including those for whom no sample had been taken (possibly appropriate) and thus may not be an accurate reflection of sample frequency in appropriate subjects.

We also examined the use of full blood counts used to monitor possible drug toxicity. Carbamazepine is associated with neutropenia, agranulocytosis and aplastic anaemia (Association of the British Pharmaceutical Industry, 1998; Cates \& Powers, 1998). Valproate can cause thrombocytopenia and, more rarely, leucopenia and pancytopenia (Balfour \& Bryson, 1994). Blood monitoring is therefore essential for both drugs. We found that full blood counts had been performed for just over three-quarters of patients, but that monitoring was infrequent. Many patients had not had counts performed for some years.

Our findings concur with studies in other, similar fields. For example, in epilepsy, anticonvulsant monitoring is strongly recommended, but often poorly done (Schoenenberger et al, 1995). In mental health patients, clear, unequivocal standards for the use of carbamazepine and valproate have not been established. However, our study has shown that, where clear guidance on prescribing is available, prescribing and monitoring often fall short of what might be considered acceptable practice. Prescribers and pharmacists need to be better aware of published guidance and to follow more closely recommendations made. Our findings also support the need for proposed clinical governance initiatives relating to the quality of prescribing.

\section{References}

ASSOCIATION OF THE BRITISH PHARMACEUTICAL INDUSTRY (1998) ABPI Compendium of Data Sheets and Summaries of Product Characteristics. London: Datapharm Publications.

BALFOUR, J. A. \& BRYSON, H. M. (1994)

Valproic acid: A review of its pharmacology and therapeutic potential in indications other than epilepsy. CNS Drugs, 2, 144-173.

CATES, M. \& POWERS, R. (1998) Concomitant rash and blood dyscrasias in geriatric psychiatry patients treated with carbamazepine. Annals of Pharmacotherapy, 32, 884-887.
EADIE, M. J. (1995) The role of therapeutic drug monitoring in improving the cost effectiveness of anticonvulsant therapy. Clinical Pharmacokinetics, 29, 29-35.

REYNOLDS, E. H. (1978) Drug treatment of epilepsy. Lancet, ii, $721-725$

SCHOENENBERGER, R. A. TANASIJEVIC, M. J., JHA, A., et al (1995) Appropriateness of antiepileptic drug level monitoring. Journal of the American Medical Association, 274, $1622-1626$. 
TAYLOR, D. \& DUNCAN, D. (1997) Doses of carbamazepine and valproate in bipolar affective disorder. Psychiatric Bulletin, 21, 221-223.
- MCCONNELL, D., MCCONNELL, H., et al (1999) The Maudsley Prescribing Guidelines (5th edn). London: Martin Dunitz Ltd.
*David M. Taylor Chief Pharmacist, South London and Maudsley NHS Trust and Honorary Senior Lecturer, Institute of Psychiatry, De Crespigny Park, Denmark Hill, London SE5 8AF, Kate Starkey Clinical Pharmacist, Hounslow \& Spelthorne Community and Mental Health NHS Trust, Saira Ginary Clinical Pharmacist, Camden \& Islington Community Health Services NHS Trust, London

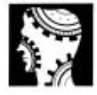

original papers

Psychiatric Bulletin (2000), 24, 177-178

INDRA I. ANGUNAWELA, ANDREW BARKER AND SIMON D. NICHOLSON

\section{The NHS and Community Care Act 1990}

Impact on the discharge profile of patients with dementia

\section{AIMS AND METHOD}

The Community Care Act came into effect in April 1993. In order to see what impact this would have on the discharge profile of dementia inpatients, prospective studies of inpatient discharges from a dementia assessment ward before the Act, and five and 41 months after the Act were conducted.

\section{RESULTS}

The proportion of patients discharged to their own homes and to residential/nursing home care remained unaffected by the Act. Duration of hospital stay increased after the Act in 1993 and 1996 $(P=0.02)$ largely due to delays in placement into care homes. Placement delay was increased both in 1993 and 1996, but by 1996 the difference was no longer statistically significant.
Duration of hospital stay was unaffected by the Act for those patients discharged to their own homes.

\section{CLINICAL IMPLICATIONS}

The new care management process by social services was found to be associated with delayed discharges for people with dementia requiring residential/nursing home placements, thus causing pressures on beds and higher in-patient costs.
The implementation of the National Health Service (NHS) and Community Care Act 1990 on 1 April 1993 made local authority social services departments responsible for organising and funding support and care in the community to "enable people affected by aging or disability to live as independently as possible". It required social services departments to use a care management process to arrange care in the community by assessing elderly inpatients for possible help after discharge from the hospital.

Concerns have been reported as to the success of the reforms (Tonks, 1993; Impallomeni \& Starr, 1994; Dean, 1995) due to the lack of funding, bed closures (both NHS and local authority) and an ever increasing elderly population. Mixed results have been reported on the discharge profile of elderly patients from hospital. While Lewis et al (1994) and Smith et al (1994) reported no difference before and after the Act, a change for the better (Ajayi et al, 1995) and a change for the worse (McAlpine \& Read, 1994; Newnham et al, 1995) after the Act, have also been reported. The Act was reported to have had little effect in reducing the institutionalisation of old people (Impallomeni \& Starr, 1995).

The aim of this study was to compare the effects of the reforms on the discharge of dementia in-patients from hospital before and after the Community Care Act by comparing: (a) the proportion of patients discharged to residential/nursing home care; (b) mean duration of hospital stay; and (c) placement delay in residential/ nursing homes following referral for care management.

\section{The study}

All admissions to the dementia assessment ward at the Forston Clinic in Dorchester during a three-month period in the years 1992, 1993 and 1996 (1 September to 30 November to avoid any seasonal bias) were followed up prospectively. Patients admitted for respite and those who were transferred or died during the admission were excluded from the study. The data collected were name, age, gender, dates of admission and discharge, placement on discharge and date of referral to social services for care management. Analysis of data was carried out with SPSS (version 6.1, 1994), using descriptive statistics and non-parametric tests (Mann-Whitney $U$ and $\chi^{2}$ tests). Examination of variables suggested non-parametric tests were most appropriate.

\section{Findings}

The mean ages (years) for the three groups were 79.6 (95\% Cl 76-82) in 1992, 79.7 (95\% Cl 77-81) in 1993 and 81.3 (95\% Cl 78-84) in 1996. There was no significant difference in age or gender in the three groups. Table 1 shows the numbers and proportion of patients discharged to residential/nursing home care and to other locations (home, sheltered/warden controlled accommodation) before and after the Act. The median length of stay in hospital for those discharged to nursing/residential homes was prolonged by 33 days in 1993 and by 19 days in 1996 as compared with 1992, prior to the Act. The differences were statistically significant (Table 1). The median length of stay for those discharged to their own 